\title{
GENERATING REAL PERSISTENT EFFECTS OF MONETARY SHOCKS: HOW MUCH NOMINAL RIGIDITY DO WE REALLY NEED?
}

\author{
Olivier Jeanne
}

Working Paper 6258 
NBER WORKING PAPER SERIES

GENERATING REAL PERSISTENT

EFFECTS OF MONETARY SHOCKS:

HOW MUCH NOMINAL RIGIDITY

DO WE REALLY NEED?

Olivier Jeanne

Working Paper 6258

http://www.nber.org/papers/w6258

\section{NATIONAL BUREAU OF ECONOMIC RESEARCH \\ 1050 Massachusetts Avenue \\ Cambridge, MA 02138 \\ November 1997}

This paper was presented at the 20th Annual International Seminar on Macroeconomics, Gerzensee, Switzerland, 16-17 June 1997. It benefited from comments by a number of participants, in particular Marianne Baxter, Bob King, Lucrezia Reichlin, and Andy Rose. The first version of the paper was also improved by comments from Tim Cogley, Greg Linden, and two anonymous referees. This paper is part of NBER's research program in Monetary Economics. Any opinions expressed are those of the author and not those of the National Bureau of Economic Research.

(C) 1997 by Olivier Jeanne. All rights reserved. Short sections of text, not to exceed two paragraphs, may be quoted without explicit permission provided that full credit, including $(\mathbb{C}$ notice, is given to the source. 
Generating Real Persistent Effects of Monetary Shocks:

How Much Nominal Rigidity Do We Really Need?

Olivier Jeanne

NBER Working Paper No. 6258

November 1997

JEL Nos. E1, E3

Monetary Economics

\begin{abstract}
This paper attempts to assess whether money can generate persistent economic fluctuations in dynamic general equilibrium models of the business cycle. We show that a small nominal friction in the goods market can make the response of output to monetary shocks large and persistent if it is amplified by real wage rigidity in the labor market. We also argue that given the level of real wage rigidity that is observed in developed countries, a small degree of nominal stickiness might be sufficient for money to produce economic fluctuations as persistent as those observed in the data.
\end{abstract}

Olivier Jeanne

CERAS

École Nationale des Ponts et Chaussées

28, rue des Saints-Pères

75007 Paris

FRANCE

jeanne@econ.berkeley.edu 


\section{Introduction}

Recent research suggests that monetary shocks do not have persistent real effects in dynamic general equilibrium models incorporating a plausible degree of price stickiness (Chari, Kehoe and McGrattan, 1996). This finding has important implications for the theory of the business cycle. Money cannot be a serious candidate for the role of driving force behind the business cycle if it cannot produce in a model the level of persistence in economic fluctuations that is observed in the data.

The purpose of the present paper is to reconsider the persistence problem when real rigidities are introduced along with nominal ones into a dynamic general equilibrium framework. It is a recurrent theme in the neo-Keynesian literature that nominal rigidities need to be supplemented by real rigidities in the goods, labor or financial markets in order to have large aggregate effects (Ball and Romer, 1990; Blanchard, 1990; Blanchard and Fischer, 1989; Romer, 1996). This insight, however, needs to be developed in an intertemporal framework in order to study the persistence of the response of output to monetary shocks. In this paper we show that a monetary theory of the business cycle may not require very pervasive or persistent nominal rigidities in the goods market if they are amplified by real rigidities in the labor market. We also show that given the level of real wage rigidity that is observed in developed countries, a small degree of nominal stickiness might be sufficient for money to produce economic fluctuations as persistent as those observed in the data.

This paper belongs to a recent strand of research that incorporates Keynesian ingredients, like nominal stickiness, to the dynamic general equilibrium framework developed by the students of the business cycle. ${ }^{1}$ In a recent paper, King and Goodfriend (1997) argue that this class of models may pave the way for a synthesis between the neo-Keynesian and New Classical approaches to macroeconomic analysis, which they coin the "New Neo-classical

${ }^{1}$ This literature counts a rapidly growing number of contributions, including Benassy (1995), Cho (1993), Cho and Cooley (1995), Cooley and Hansen (1995), Hairault and Portier (1993), Ireland (1996), Jeanne (1994), Kiley (1997), Kimball (1995), King (1997), King and Watson (1996), Ohanian, Stockman and Kilian (1995), Rotemberg (1996), and Yun (1996). See also Kollmann (1996) and Obstfeld and Rogoff (1995) in an open-economy context. It is reviewed in Nelson (1997). 
Synthesis".2 The ambition of the New Neoclassical Synthesis (NNS hereafter) is to introduce into the class of macro-models traditionally used by policymakers the power of general equilibrium analysis.

Because they incorporate nominal stickiness, NNS models allow monetary shocks to affect output in a non-trivial way. ${ }^{3}$ Until now, however, NNS models have failed to make a convincing case that money can generate persistent economic fluctuations. This failure is a reflection of a more general problem of dynamic general equilibrium models, which is their lack of a strong endogenous propagation mechanism (Cogley and Nason, 1995; Hall, 1997). As a result, nominal prices need to be fixed for periods of more than three years on average for monetary shocks to generate output fluctuations that are as persistent as in the data. ${ }^{4}$ While somes goods, like magazines, have been observed to keep the same price for several years in a row, it is generally believed that in the economy as a whole the persistence of nominal price rigidity should be a matter of quarters, not years.

One way to reconcile frequent price revision at the individual level and considerable price sluggishness in the aggregate is to assume that prices are set in a staggered way. In a classic paper, Taylor (1980) showed that staggered wage contracts as short as one year can generate persistence in output similar to that observed in postwar business cycles. Blanchard (1983) showed that such results also hold when firms set prices in a staggered fashion. In a recent paper, however, Chari, Kehoe and McGrattan (1996) argue that price staggering fails to produce significant persistence once it is considered in a dynamic general equilibrium framework. They simulate the response of output to a money shock in a series of different dynamic stochastic general equilibrium models with price staggering $\dot{a}$ la Taylor, and find in all cases that the persistence of output response does not exceed the duration of the

\footnotetext{
${ }^{2}$ Kimball (1995) proposes the name of "neo-monetarist" for dynamic general equilibrium model with short-term nominal stickiness.

${ }^{3}$ In dynamic general equilibrium models without nominal rigidities or other market imperfections, the only way money can influence real activity is through the intertemporal inflation tax, and this effect is very small (Cooley and Hansen, 1989; Kydland, 1991).

${ }^{4}$ Hairault and Portier, 1993; King and Watson, 1996; Kollmann, 1996; and Yun, 1996 assume degrees of nominal stickiness of that order of magnitude. They generally refer to the early work of Rotemberg (1982), who estimated that nominal prices should be fixed for periods of more than three years to account for the observed correlations between money, prices and output.
} 
nominal price contracts, i.e., a few quarters. The persistence problem, hence, seems to remain intact.

The present paper reconsiders the persistence problem in the context of a simple NNS model, which we have chosen to keep very stylized in several respects. In particular, we have not included in the model any of the ingredients that are known to generate persistence in dynamic general equilibrium models, like capital accumulation or time to build. These channels have already been shown to be very weak, ${ }^{5}$ and assuming them away allows us to focus attention on the key point of this paper, i.e., the persistence arising from the combination of nominal and real rigidities.

The simplicity of the model allows us to adopt an analytical approach to the persistence problem, as opposed to the simulation method adopted in many papers. We can solve the model explicitly (around a steady state) and derive a formula giving output persistence as a function of an index representing nominal price rigidity and an index representing real wage rigidity. It is then possible to make general statements on how nominal price and real wage rigidities complement each other in generating persistence in output fluctuations, and interpret them precisely.

We then proceed to calibrate the model and see whether, given a plausible degree of real wage rigidity, money can have large and persistent effects with small nominal friction. We show that given the level of real wage rigidity that is assumed by Ball and Romer (1990) in the calibration of their model, nominal prices do not need to be fixed for very long periods (two or three quarters on average) to account for the observed persistence of output. We also provide some evidence that the calibration of Ball and Romer is consistent with the cyclical behavior of real wages in developed economies.

The closest precursor to our study is the paper by Kimball (1995). Kimball (1995) presents a dynamic general equilibrium with nominal stickiness and shows that real rigidity in Ball and Romer's sense makes price adjustment slow in comparison to the frequency at which individual firms adjust

\footnotetext{
${ }^{5}$ See Cogley and Nason (1995), and Rouwenhorst (1991). Some authors have shown that modified versions of the benchmark model exhibit more potent propagation channels. For example, Horvath (1997) shows that non-persistent sectoral shocks can lead to persistent aggregate fluctuations.
} 
their prices. Our paper is also closely related to an unpublished paper developed independently by Kiley (1997). The main difference with the analysis presented here is that the real rigidities considered by Kiley (1997) come from increasing returns to scale in production. Kiley emphasizes the fact that this feature is also conducive to equilibrium indeterminacy or sunspot fluctuations. By putting the real rigidity in the labor market, the present paper naturally leads to the discussion of a different set of issues, and makes a first step towards analysing the relationship between labor market institutions and the role of monetary policy in the business cycle.

The paper is structured as follows. The next section presents the assumptions of the model. Section 3 characterizes the cyclical properties of output around the steady state, and how they depend on the extent of nominal price and real wage rigidities. Section 4 discusses the properties of a calibrated version of the model, and section 5 concludes.

\section{The model}

This section presents the assumptions of a stylized model that we use as our benchmark framework of analysis in the following sections. There are three types of agents in the economy, households, firms and the government. Households and firms optimize intertemporally on the basis of rational expectations. In accordance with the NNS approach, firms set their prices in a monopolistic way and do not adjust them instantaneously to changes in the economic conditions. Nominal price stickiness is modeled as in Calvo's (1983) model of staggered contracts. Households use money because of a cash-in-advance constraint, and the only shocks to the economy come from money supply. A key feature of the model is real wage rigidity. Following Romer (1996), we model the determination of the real wage by a real wage function that may represent a variety of wage setting mechanisms.

\subsection{Households and firms}

There is a continuum of differentiated goods $j \in[0,1]$ that are supplied by monopolistic producers and consumed by households. Households consume a composite good, defined by the CES index: 


$$
Y \equiv\left(\int_{0}^{1} Y_{j}^{\frac{a-1}{a}} d j\right)^{\frac{a}{a-1}}
$$

where the elasticity of substitution between goods, $a$, is assumed to be strictly larger than one. It follows that the demand for good $j$ is given by:

$$
Y_{j}=\left(\frac{P_{j}}{P}\right)^{-a} Y
$$

where $Y$ is aggregate demand and the price index $P$ is given by:

$$
P \equiv\left(\int_{0}^{1} P_{j}^{1-a} d j\right)^{\frac{1}{1-a}}
$$

Households are identical and their number is normalized to 1 , so that aggregate and per capita quantities are the same in equilibrium. At date $t$ the representative household maximizes:

$$
U_{t}=E_{t}\left(\sum_{s=0}^{+\infty} \beta^{s}\left[u\left(c_{t+s}\right)-v\left(l_{t+s}\right)\right]\right)
$$

where $c_{t+s}$ and $l_{t+s}$ are the consumption of the composite good and the labor supply of the household at time $t+s$. The utility of consumption and the disutility of labor satisfy the standard conditions $u^{\prime}(\cdot)>0, u$ " $(\cdot)<0$ and $v^{\prime}(\cdot)>0, v^{\prime \prime}(\cdot)>0$.

The sequence of events at time $t$ is as follows. The representative household enters period $t$ with $n_{j t-1}$ shares of firm $j, b_{t-1}$ nominal bonds, and $m_{t-1}$ nominal money. It receives a lump-sum monetary transfer $z_{t}$ from the government before the financial market opens. The assets traded in the financial market are shares, bonds and money. The household reallocates its portfolio under the constraint:

$$
m_{t-1}+z_{t}+\left(1+i_{t-1}\right) b_{t-1}+\int_{0}^{1} n_{j t-1} Q_{j t} d j=m_{t}^{h}+b_{t}+\int_{0}^{1} n_{j t} Q_{j t} d j
$$

where $Q_{j t}$ denotes the price of share $j$ at $t$ and $m_{t}^{h}$ is the individual's money holdings at $t$. 
Households supply labor and production then takes place. Once the goods are produced, the goods market opens, in which households purchase the consumption good under the cash-in-advance constraint:

$$
P_{t} c_{t} \leq m_{t}^{h}+P_{t} W_{t}\left(l_{t}-L_{t}\right)
$$

where $L_{t}$ is the aggregate labor supply and $W_{t}$ is the real wage. This equation means that while households must use cash to buy goods, they receive inkind compensation for the hours worked in excess of the equilibrium work hours. ${ }^{6}$

Households then receive wages and dividends from the firms, which makes their end-of-period money holdings equal to:

$$
m_{t}=W_{t} P_{t} L_{t}+\int_{0}^{1} n_{j t} D_{j t} d j
$$

where $D_{j t}$ denotes the nominal dividend paid by firm $j$ to its shareholders, given by:

$$
D_{j t}=P_{j t} Y_{j t}-P_{t} W_{t} L_{j t}
$$

The only production input is labor. All producers use a linear technology that transforms one unit of labor into one unit of any differentiated good:

$$
Y_{j t}=L_{j t}
$$

(we consider the case with decreasing returns to labor in section 3.3 ).

\section{$2.2 \quad$ Rigidities}

We assume that producers optimize their nominal price at infrequent time intervals. The sluggishness in the revision of prices is modeled as in Calvo's

\footnotetext{
${ }^{6}$ Of course, in equilibrium the individual and aggregate labor supplies are the same $\left(l_{t}=L_{t}\right)$, so that money holdings are equal to nominal consumption, as in the most standard formulation of the cash-in-advance constraint. Modifying the cash-in-advance constraint in this way allows us to get rid of the inflation tax on labor supply, which, we think, should not play an important role in a theory of labor supply, at least for moderate inflation rates. The purpose of assuming away the inflation tax on labor supply is to make competitive labor supply a particular case of the real wage function (13) (otherwise the real wage would also depend on the expected rate of inflation).
} 
(1983) model of staggered price setting. At each period, a randomly selected fraction $\phi$ of producers revise their nominal price according to the simple indexation rule:

$$
P_{j t}=(1+\bar{\pi}) P_{j t-1}
$$

where $\bar{\pi}$ is the average inflation rate. The remaining $1-\phi$ producers choose $P_{j t}$ so as to maximize the value of their shares, given by:

$$
Q_{j t}=\frac{P_{t}}{u^{\prime}\left(c_{t}\right)} E_{t}\left(\sum_{s=0}^{+\infty} \beta^{s+1} \frac{u^{\prime}\left(c_{t+s+1}\right)}{P_{t+s+1}} D_{j t+s}\right)
$$

(where dividends have a time subscript 1 less than the discount factor because they are not consumed until one period after their receipt).

Competition is monopolistic in the sense that producers, when they have the opportunity to set their price in an optimizing way, take as given the aggregate demand and the prices charged by the other firms, and choose their own price $P_{j}$ taking into account the effect of $P_{j}$ on their current and future sales.

Parameter $\phi$ reflects the extent of nominal price rigidity. At any given period, the probability of being allowed to reoptimize their price is $1-\phi$ for all firms, regardless of the time elapsed since the last price optimization. Thus the average duration of price fixity is given by:

$$
\tau=(1-\phi) 0+\phi(1-\phi) 1+\phi^{2}(1-\phi) 2+\ldots=\frac{\phi}{1-\phi}
$$

It is equal to zero in the absence of nominal price rigidity $(\phi=0)$ and plus infinity when firms never revise their prices $(\phi=1)$.

As in Romer (1996, p.220), we assume that the determination of the real wage may be described by a "real wage function" of the type:

$$
W_{t}=\omega\left(L_{t}, Y_{t}\right)
$$

This formulation allows us to model real wage rigidity in a tractable and flexible way. It is consistent with a wide variety of assumptions about the process determining the real wage. For example, following one of the 
approaches to modeling unions proposed by McDonald and Solow (1981, p.903), we may assume that the union is concerned by the fairness of the division of total income between labor and capital. ${ }^{7}$ If the union determines the wage so as to make the share of labor in total income, $W L / Y$, equal to a "fair" level $k(Y)$, the real wage function becomes:

$$
\omega(L, Y)=k(Y) \frac{Y}{L}
$$

While equation (13) may result from other imperfections of the labor market, ${ }^{8}$ it is also consistent with the assumption that the labor market is perfectly competitive. In the latter case, the first order condition characterizing labor supply $v^{\prime}(l)=W u^{\prime}(c)$, together with the equilibrium conditions $c=Y$ and $l=L$, imply:

$$
\omega(L, Y)=\frac{v^{\prime}(L)}{u^{\prime}(Y)}
$$

Hereafter we take the real wage function $\omega(\cdot, \cdot)$ as given, without specifying the model of labor supply of which it is the reduced form. We say that the real wage is rigid when it is not very sensitive to the economic conditions, i.e., if the derivatives $\omega_{L}$ and $\omega_{Y}$ are small.

\subsection{Equilibrium}

Given an exogenous stochastic process for money, an equilibrium can be defined as a set of stochastic processes for the endogenous variables that satisfy the individual optimization conditions of households and firms and the aggregate equilibrium conditions. A priori, the state of the economy at any given time $t$ might seem quite complex since it involves the price setting decisions taken by producers at all previous periods. The structure of Calvo's model, however, makes possible to reduce dramatically the dimension of the

\footnotetext{
${ }^{7}$ Admittedly, the reason why the union cares about the share of labor in total income must rely on some heterogeneity in the distribution of capital in the population, which is not present in our representative agent framework.

${ }^{8}$ For example, efficiency wages $\grave{a}$ la Shapiro-Stiglitz; see Romer (1996, chapt. 10). Danthine and Donaldson (1990) introduce efficiency wage considerations into a dynamic general equilibrium model using a reduced form real wage function analogous to (13).
} 
state variable, by reducing the description of prices to two variables. In order to see this, let us consider Fix $(t)$, the set of producers that do not optimize at $t$, and Flex $(t)$, the set of producers that do. Hereafter we call these producers respectively fix-price and flex-price producers at time $t .^{9}$ All flex-price producers are faced with the same optimization problem and so choose to set their respective prices at the same level, which we denote by $P_{f l e x, t}$. Fix-price producers have heterogeneous prices, since they have chosen them at different times in the past, but it is possible to characterize the law of evolution of the index aggregating their prices, $P_{f i x, t}$, in a simple way. By definition $P_{f i x, t}$ is given by:

$$
P_{f i x, t}^{1-a} \equiv \frac{1}{\phi} \int_{j \in F i x(t)} P_{j t}^{1-a} d j
$$

Using $P_{j t}=(1+\bar{\pi}) P_{j t-1}$, this expression may be rewritten:

$$
P_{f i x, t}^{1-a}=(1+\bar{\pi})^{1-a} \frac{1}{\phi} \int_{j \in F i x(t)} P_{j t-1}^{1-a} d j
$$

but as $F i x(t)$ is a randomly chosen sample of size $\phi$ :

$$
\frac{1}{\phi} \int_{j \in F i x(t)} P_{j t-1}^{1-a} d j=P_{t-1}^{1-a}
$$

so that $P_{f i x, t}$ is the following simple function of the aggregate price level and the inflation rate $\pi_{t} \equiv P_{t} / P_{t-1}-1$ :

$$
P_{f i x, t}=\frac{1+\bar{\pi}}{1+\pi_{t}} P_{t}
$$

Plugging this equation into $P_{t}^{1-a}=\phi P_{f i x, t}^{1-a}+(1-\phi) P_{f l e x, t}^{1-a}$ provides a relationship between the inflation rate and the ratio of the price set by flexprice producers to the aggregate price index $\tilde{P}_{\text {flex }, t} \equiv P_{f l e x, t} / P_{t}$ :

\footnotetext{
${ }^{9}$ While this terminology simplifies the exposition, it is important to keep in mind that fix-price or flex-price characterizes the state of a producer for only one period: a flex-price producer at one period can be fix-price in the following period. Note also that fix-price producers do not maintain their prices literally fixed (except in the case $\bar{\pi}=0$ ).
} 


$$
1=\phi\left(\frac{1+\bar{\pi}}{1+\pi_{t}}\right)^{1-a}+(1-\phi) \tilde{P}_{f l e x, t}^{1-a}
$$

Now that the description of the economy has been simplified, we may state the general definition of an equilibrium. We assume that the rate of money growth:

$$
\mu_{t} \equiv \frac{M_{t}}{M_{t-1}}-1
$$

follows an $\operatorname{AR}(1)$ stochastic process with mean $\bar{\mu}$ :

$$
\mu_{t}-\bar{\mu}=\rho_{m}\left(\mu_{t-1}-\bar{\mu}\right)+\epsilon_{t}
$$

where $\epsilon$ is an i.i.d. variable with mean zero. We restrict the attention to equilibria in which the cash-in-advance constraint is binding, and denote by $M_{t}^{r}=M_{t} / P_{t}$ and $m_{t}^{r h}=m_{t}^{h} / P_{t}$ the aggregate and individual real money holdings. We assume that the aggregate supply of bonds is zero.

An equilibrium, then, is set of individual decision rules and aggregate rules that satisfy:

*optimization by households: $m^{r h}(\cdot), n_{j}(\cdot)_{j \in[0,1]}, b(\cdot), c(\cdot)$ maximize the utility of the representative household (4) subject to $(5)$ and $(6)$, and the latter constraint is binding, i.e., $c(\cdot)=m^{h r}(\cdot)+W(\cdot)(l(\cdot)-L(\cdot))$;

* optimization by producers: $\tilde{P}_{f l e x}(\cdot)$ maximizes the share value $(11)$ subject to the demand constraint (2);

* goods market equilibrium: $\pi(\cdot)$ and $\tilde{P}_{f l e x}(\cdot)$ satisfy $(17)$ and $c(\cdot)=Y(\cdot)$;

* financial market equilibrium: $\forall j \in[0,1], n_{j}(\cdot)=1, b(\cdot)=0$;

${ }^{*}$ wage equation: $W(\cdot)=\omega(L(\cdot), Y(\cdot))$;

${ }^{*}$ money market equilibrium: $M^{r}(\cdot)=m^{h r}(\cdot)$ and:

$$
1+\mu_{t}=[1+\pi(\cdot)] \frac{M^{r}(\cdot)}{M_{t-1}^{r}}
$$




\section{Money and output around steady state}

We first linearize the economy around a steady state, showing in particular that the channels through which money operates can be interpreted through the traditional Keynesian notions of aggregate demand and aggregate supply (section 3.1). We then study how real and nominal rigidities complement each other to increase the persistence of the response of output to money shocks (section 3.2), before we check the robustness of our results to changes in the assumptions (section 3.3 ).

\subsection{The linearized model: IS-LM are back}

We proceed through the usual steps to study small fluctuations of the economy around the steady state. First, we write the relevant first order conditions for the individual optimization problems. We then characterize the steady state with constant money growth, before linearizing the economy.

Two first order conditions are necessary and sufficient to characterize the equilibirum. The first one equates the marginal utility of consumption to the marginal utility of saving:

$$
u^{\prime}\left(c_{t}\right)=\beta E_{t}\left(\frac{1+i_{t}}{1+\pi_{t+1}} u^{\prime}\left(c_{t+1}\right)\right)
$$

The second condition gives the optimal price setting decision of flex-price producers (derivation in Appendix):

$$
\tilde{P}_{\text {flex }, t}=\frac{a}{a-1} \frac{E_{t}\left(\sum_{s=0}^{+\infty}(\beta \phi)^{s} \frac{u^{\prime}\left(c_{t+s+1}\right)}{1+\pi_{t+s+1}} Y_{t+s}\left[\frac{P_{t+s}}{(1+\bar{\pi})^{s} P_{t}}\right]^{a} W_{t+s}\right)}{E_{t}\left(\sum_{s=0}^{+\infty}(\beta \phi)^{s} \frac{u^{\prime}\left(c_{t+s+1}\right)}{1+\pi_{t+s+1}} Y_{t+s}\left[\frac{P_{t+s}}{(1+\bar{\pi})^{s} P_{t}}\right]^{a-1}\right)}
$$

In a steady state with a constant rate of money growth $\mu_{t}=\bar{\mu}$, the inflation and nominal interest rates are given by:

$$
\begin{aligned}
\bar{\pi} & =\bar{\mu} \\
\bar{\imath} & =\frac{1+\bar{\mu}}{\beta}-1
\end{aligned}
$$

The steady state level of the real wage implied by (22) is: 


$$
\bar{W}=\frac{a-1}{a}
$$

which, together with equation (13) and $\bar{L}=\bar{Y}$, yields the following equation for the level of output:

$$
\omega(\bar{Y}, \bar{Y})=\frac{a-1}{a}
$$
$\bar{Y}$.

We assume that $\omega(\cdot, \cdot)$ is such that this equation has one unique solution

We linearize the model around the steady state, writing $X_{t}=\bar{X}\left(1+\widehat{x}_{t}\right)$ for $X=Y, W, M^{r}$ and $x_{t}=\bar{x}\left(1+\widehat{x}_{t}\right)$ for $x=i, \pi, \mu$. The linearized version of the model may be computed as (see Appendix):

$$
\begin{aligned}
\widehat{y}_{t} & =-\sigma_{u}\left(\widehat{\imath}_{t}-E_{t} \hat{\pi}_{t+1}\right)+E_{t} \widehat{y}_{t+1} \\
\widehat{m}_{t} & =\widehat{y}_{t} \\
\widehat{y}_{t} & =\frac{\alpha \phi}{(1-\phi)(1-\beta \phi)}\left(\widehat{\pi}_{t}-\beta E_{t} \widehat{\pi}_{t+1}\right) \\
\widehat{w}_{t} & =\frac{1}{\alpha} \widehat{y}_{t} \\
\hat{\mu}_{t} & =\widehat{\pi}_{t}+\widehat{m}_{t}-\widehat{m}_{t-1}
\end{aligned}
$$

The first three equations may be interpreted as a (IS)-(LM)-(AS) framework. Equation (23) reflects the intertemporal allocation of consumption. A rise in the real interest rate lowers current consumption with respect to future consumption, the strength of this effect depending on the degree of intertemporal substituability in consumption, characterized by the elasticity $\sigma_{u}=-u^{\prime}(\bar{Y}) / u^{\prime \prime}(\bar{Y}) \bar{Y}$. As output is equal to consumption in this model, the equation characterizing the intertemporal allocation of consumption is similar to the traditional (IS) equation, except for the presence of expected output on the right-hand side (see McCallum and Nelson, 1997). 
Equation (24) characterizes the demand for real money balances. Because of the cash-in-advance constraint, real money is simply proportional to output. ${ }^{10}$

Equation (25) gives aggregate supply as a function of current and expected inflation. It is called by Roberts (1995) the "new Keynesian Phillips curve". This equation may be interpreted as the result of two effects. On the one hand the supply of fix-price producers is increasing with inflation, because a rise in the general price level makes their goods cheaper relative to those supplied by flex-price producers. On the other hand, the supply of flex-price producers is decreasing with expected inflation. Higher expected future price levels induce flex-price producers to raise their prices today because they may be unable to revise them tomorrow. Note that the aggregate supply resulting from these two effects is different from the traditional expectations-augmented Phillips curve, in which output is increasing with the difference between realized and expected inflation.

Equation (26) describes how the real wage is correlated with output around steady state. Coefficient $\alpha$, given by:

$$
\alpha \equiv \frac{\omega(\bar{Y}, \bar{Y})}{\bar{Y}\left[\omega_{L}(\bar{Y}, \bar{Y})+\omega_{Y}(\bar{Y}, \bar{Y})\right]}
$$

reflects the degree of real wage rigidity in the labor market. Hereafter we call $\alpha$ the real wage rigidity index. In the fair wage model (14), it is equal to $k(\bar{Y}) / \bar{Y} k^{\prime}(\bar{Y})$. When the labor market is perfectly competitive, the real wage rigidity index is given by:

$$
\alpha=\frac{\sigma_{u} \sigma_{v}}{\sigma_{u}+\sigma_{v}}
$$

where $\sigma_{v}=v^{\prime}(\bar{Y}) / v^{\prime \prime}(\bar{Y}) \bar{Y}$ is the elasticity of labor supply. In general we assume that the real wage rigidity index is positive.

\footnotetext{
${ }^{10}$ In a more general framework with money in the utility function, this equation would take the form of a traditional (LM) equation, in which the velocity of money would depend on the nominal interest rate.
} 


\subsection{Output persistence}

Substituting $\widehat{m}_{t}$ and $\hat{\pi}_{t}$ out of (24), (25) and (27) gives a second order stochastic difference equation linking output and money growth:

$$
\widehat{y}_{t-1}-\left[1+\beta+\frac{(1-\phi)(1-\beta \phi)}{\alpha \phi}\right] \widehat{y}_{t}+\beta E_{t} \widehat{y}_{t+1}=\beta E_{t} \widehat{\mu}_{t+1}-\widehat{\mu}_{t}
$$

Using standard techniques, the solution to this equation may be written:

$$
\widehat{y}_{t}=\rho \widehat{y}_{t-1}+\rho \frac{1-\beta \rho_{m}}{1-\beta \rho \rho_{m}} \widehat{\mu}_{t}
$$

where $\rho$ is the root between zero and one of the equation:

$$
1-\left[1+\beta+\frac{(1-\phi)(1-\beta \phi)}{\alpha \phi}\right] \rho+\beta \rho^{2}=0
$$

Coefficient $\rho$ characterizes both the amplitude and the persistence of the response of output to money shocks. Equation (32) defines this coefficient as an implicit function of the nominal price and real wage rigidity indices $\phi$ and $\alpha$. Using this equation it is straightforward to show that:

Proposition 1 . The amplitude and persistence of the response of output to a monetary shock are increasing with the degree of nominal price and real wage rigidities:

$$
\frac{\partial \rho}{\partial \phi}>0 \quad \frac{\partial \rho}{\partial \alpha}>0
$$

Real wage rigidity increases the amplitude of the output response to a monetary shock for the same reason as in Ball and Romer (1990). The impact of money on output is large if flex-price producers react to a rise in nominal demand by raising their supply more than their prices. In a static model like that of Ball and Romer (1990) flex-price producers determine their price without taking into account the implications of their current price setting for the future. Their relative price is then given by equation (22) with $\phi=0$, i.e.: 


$$
\tilde{P}_{f l e x, t}=\frac{W_{t}}{\bar{W}}
$$

The only reason why flex-price producers raise their price is that the rise in labor demand by fix-price producers bids up the real wage above its natural level. So the more rigid the real wage, the less flex-price producers adjust their prices and the more they adjust their quantities.

Proposition 1 states that real and nominal rigidities influence not only the amplitude but also the persistence of the output response to a monetary shock. The reason why the output deviations produced by monetary shocks need more time to die away is the following. If there is more nominal rigidity each producer has to wait a longer time on average before it can adjust its price to the monetary shock. And if the real wage is more rigid the price adjustment, when it takes place, is smaller. There is another, more subtle, reason why the amplitude and the persistence of output fluctuations are positively related in this model. If the response of output to a monetary shock is more persistent, then the price level increases at a slower pace following a shock, and the expected inflation rate is lower. But since the supply of flex-price producers is decreasing with the expected rate of inflation, the amplitude of the output response is also larger.

Proposition 1 states that real wage rigidity and nominal price rigidity act as substitute inputs in the production of output persistence. Pursuing the analogy with the inputs in a production function, one may characterize the substitutability between the two types of rigidity by building the iso- $\rho$ curves in the space $(\phi, \alpha)$, i.e., the curves of equation:

$$
\alpha=\frac{\rho}{\phi} \frac{(1-\phi)(1-\beta \phi)}{(1-\rho)(1-\beta \rho)}
$$

Figure 1 shows a set of such curves for $\beta=0.99$ and different values of output persistence $\rho$. These curves are flat around $\phi=1$, which means that in order to explain a given level of output persistence, a small increase in real rigidity may be sufficient to offset a large decrease in nominal rigidity. This non-linearity is important for our results: it implies that one may not need to assume implausibly large levels of real wage rigidity in order to reduce the degree of nominal stickiness to more realistic levels than those implied by earlier NNS models. 


\subsection{Robustness}

We explore in this section the extent to which the results obtained above are robust to two changes in the assumptions: a more general specification of the production function, and a change in the structure of price staggering.

We first consider a generalized version of the model, in which labor may exhibit decreasing returns. Let us assume that the production function (9) becomes:

$$
Y_{j}=L_{j}^{\gamma} \quad 0<\gamma \leq 1
$$

Proceeding through the same steps as in the preceding section, ${ }^{11}$ it is possible to show that the deviation in output still follows equation (31), where $\rho$ is now the root of:

$$
1-\left[1+\beta+\frac{(1-\phi)(1-\beta \phi)}{\alpha \phi} \frac{\gamma+\alpha(1-\gamma)}{\gamma+a(1-\gamma)}\right] \rho+\beta \rho^{2}=0
$$

The analysis presented in the preceding section corresponds to the case with constant returns to labor $\gamma=1$. What is the effect of having decreasing returns to labor? First, using equation (37) it is not difficult to see that Proposition 1 remains true. Second, the comparison of (32) and (37) shows that if $\alpha$ is smaller than $a$, coefficient $\rho$ is larger with decreasing returns to labor than with constant returns. ${ }^{12}$ As the elasticity of substitution between goods is usually assumed to be close to 10 (in order to produce a markup of $10 \%$ ), the persistence of output is in fact larger in the model with decreasing returns to labor than in our benchmark model as long as the real wage rigidity index is smaller than 10 .

The second variation that we consider is to replace price staggering $\grave{a} l a$ Calvo by price staggering $\grave{a}$ la Taylor. We now assume that each producer

\footnotetext{
${ }^{11}$ The details of the computation are available from the author on request.

${ }^{12}$ The intuition behind this result is the following. In general the amplitude and persistence of the output response to a monetary shock are larger if the marginal cost of production is less procyclical. Decreasing returns to labor have an ambiguous impact on the cyclical behavior of the marginal cost production. They make the equilibrium marginal cost of production more sensitive to demand but less sensitive to the real wage level. If the real wage is not too rigid, decreasing returns to labor can make the marginal cost of production less procyclical.
} 
optimizes every two periods, and that at each period, one half of the producers determine their prices for the current and next period. Going through the same steps as before, it is possible to show that $\hat{y}_{t}$ follows $(31)$, where $\rho$ is now the solution of:

$$
1+\beta-\left(1+2 \beta+\frac{1}{\alpha}\right) \rho+\beta \frac{\alpha-1}{\alpha} \rho^{2}=0
$$

The equation above should be compared to (32) with $\phi=1 / 2$ (which is the value of $\phi$ that generates the same average length of nominal price contracts in the benchmark model). Figure 2 shows the values of $\rho$ in function of $\alpha$ that are produced by equations (32) and (38). In fact, price staggering $\grave{a}$ la Taylor seems to produce slightly more persistence than Calvo's contracts.

The comparison might be different when the average duration of nominal contracts is longer than one. The two types of price staggering are then less easy to compare because the dynamics of output in Taylor's model become more complicated. ${ }^{13}$ But as limited as it is, our comparison suggests that the properties of our model do not hinge sensitively on the way price staggering is modeled.

\section{A look at the data: how much rigidity do we need?}

This section attempts to determine whether plausible levels of real wage rigidity, $\alpha$, and nominal price stickiness, $\phi$, can generate a level of persistence in output fluctuations, $\rho$, that is consistent with the data? We first determine a plausible range of values for the nominal price and real wage rigidity indices, and then discuss whether these values can generate a response to monetary shocks that is consistent with the time series properties of output.

\footnotetext{
${ }^{13}$ For example, if one third of the producers set their prices every three periods, $\rho$ is the root of a third degree equation in Taylors's model. A nice feature of Calvo's contracts is that one can continuously vary the degree of nominal stickiness without changing the degree of the equation of which $\rho$ is a root.
} 


\subsection{Nominal price rigidity}

The direct microeconomic evidence on nominal rigidity is rather scarce, probably due to the difficulty of gathering large data sets. The empirical literature typically gives estimates of the average length of spell for which nominal price remains unchanged, which corresponds to variable $\tau$ in our model. The considerable nominal stickiness in the price of magazines found by Cechetti (1986) seems specific to this particular good. Carlton (1986), in his study of intermediate goods transactions between buyers and sellers having long-term relationships, finds that the average length of spell for which price remains unchanged in a given transaction is slightly lower than three quarters. While one might have expected the price of retail goods to be more flexible than that of intermediate goods, Kashyap (1985) actually finds more stickiness than Carlton in the prices of retail goods in mail order catalogs, with an average time between price changes close to 5 quarters. Lach and Tsiddon (1992) find a shorter duration of price quotation (about two months) in their study of the price setting for food products in a sample of Israeli stores, which may be related to the fact that the inflation rate was markedly higher than in the previously mentioned studies.

Overall, we would argue that a plausible calibration of nominal stickiness would be to assume that prices remain fixed for three quarters on average, i.e. $\phi=3 / 4$. We show below that our results are not very sensitive to this specific value. Assuming instead two or four quarters of nominal stickiness does not affect our conclusions.

\subsection{Real wage rigidity}

The literature offers a number of models of real wage rigidity based on efficiency wage mechanisms, insider/outsider relationships, or implicit contracts. These models are usually very stylized, and have not been constructed and estimated in a way that produces estimates corresponding to variable $\alpha$ in the model. Ball and Romer (1990) simply adopt the calibration $\alpha=10$ as an "empirically plausible base case" and present some sensitivity analysis around this value. It seems reasonable, from this perspective, to adopt the interval $[5,15]$ as a plausible range of values for $\alpha$. 
Another approach to the calibration of $\alpha$ is to consider the cyclical behavior of the real wage. The view that the real wage is rigid is often justified by the stylized fact that the real wage is mildly procyclical or acyclical (see, e.g., Geary and Kennan, 1982). This stylized fact has been challenged by Bils (1985) and Solon, Barsky, and Parker (1994), who argue that the procyclicality of the real wage is biased downwards in the data because of the changing composition of the employed labor force, and find strongly procyclical wages after controlling for this composition bias. Keane, Moffitt and Runkle (1988) argue, however, that the composition bias acts in the other direction and tends to exaggerate the procyclicality of wages.

Again, the empirical literature on the cyclical properties of the real wage does not produce an estimate that could be directly identified with coefficient $\alpha$ in our model. Thus we attempted to estimate equation (26) directly, using quarterly data on six developed countries. ${ }^{14}$ Variables $\hat{y}_{t}$ and $\hat{w}_{t}$ were operationalized as the deviations of the (logarithms of the) output and real wage levels from deterministic trends. Using other detrending methods, like Hodrick-Prescott or bandpass filtering, would not affect our conclusions. Equation (26) was estimated in first differences because of the possible nonstationarity of the variables:

$$
\Delta \widehat{w}_{t}=\frac{1}{\alpha} \Delta \widehat{y}_{t}+\nu_{t}
$$

Before proceeding with the discussion of the results, it bears emphasizing that the purpose of regression (39) is not to estimate a wage equation. Admittedly this regression is much too crude for that: it lacks dynamics, and there is no correction for the endogeneity of the regressor. Our purpose is simply to produce a piece of evidence suggesting that the benchmark calibration of Ball and Romer is not inconsistent with the cyclical behavior of the real wage, at least to a first approximation.

The results of the estimation are given in the second column of Table 1. The estimates of $1 / \alpha$ are small and positive (except in the case of France),

${ }^{14}$ The countries that we consider are the United States, Japan, Germany, France, Italy, and the United Kingdom over the period 1979:1-1992:4. The data are taken from the International Financial Statistics (IFS) CD-ROM. The output $Y$ is real GDP (line 99). The real wage $W$ corresponds to the measure of earnings given at line 65 of the IFS, deflated by the CPI index (line 64). 
so that the real rigidity index $\alpha$ is found to be rather large, between 5 and 15 for all countries but France and the UK. Furthermore, a range of values $\alpha \in[5,15]$ implies an interval for $1 / \alpha$ which falls inside the $95 \%$ confidence interval of the estimation for all countries except the UK.

For the sake of comparison, it is worth noting that values of $\alpha$ between 5 and 15 are difficult to reconcile with the assumption of a perfectly competitive labor market. If the labor supply is perfectly competitive, $\alpha$ is given by equation (29). The value of $\alpha$ then results from the calibration of the intertemporal elasticity of substitution $\sigma_{u}$ and the elasticity of labor supply $\sigma_{v}$. On the basis of a number of studies of disaggregated labor market data, most labor economists agree that the elasticity of labor supply $\sigma_{v}$ is smaller than one (Pencavel, 1986), and this is the order of magnitude that is usually used in the calibration of dynamic general equilibrium models of the business cycle. It is easy to see, going back to equation (29), that if $\sigma_{v}$ (or $\sigma_{u}$ ) is smaller than one, $\alpha$ cannot be greater than one. The log-log utility function that is used in many models (King et al, 1988; King and Watson, 1996; Ohanian et al, 1995) imply $\sigma_{u}=1, \sigma_{v}=1$ and $\alpha=1 / 2$. As a consequence, these models typically predict that the number of hours worked and the real wage should be strongly correlated along the business cycle, a prediction that fails to materialize in the aggregate data (Christiano and Eichenbaum, 1992; Danthine and Donaldson, 1990).

\subsection{Ouput persistence}

The empirical identification of $\rho$ requires some assumptions about the stochastic process governing output. Ideally, these assumptions should be consistent both with the data and with the model. Equation (31) defines the deviation of output from trend as an $\operatorname{AR}(2) .{ }^{15}$ While very simple, this formulation seems an acceptable one in view of the literature on the time-series properties of output, in particular Cochrane's (1988) conclusion that "an AR(2) about a deterministic trend...is a good in-sample characterization of the behavior of GNP". Thus a simple and model-consistent way to estimate $\rho$ is

\footnotetext{
${ }^{15}$ While in equation (31) the only shock is monetary, it is not difficult to see that a stochastic AR(1) labor productivity shock would appear in equation (31) with the same persistence $\rho$ as the monetary shock.
} 
to estimate the output process as an $\operatorname{AR}(2)$ around a trend and identify $\rho$ as its larger root. The results are given in the first column of Table 1.

Can the model attribute to monetary shocks a level of output persistence close to that observed in the data for plausible levels of price and wage rigidities? We attempt to address this question in two different ways. First, we compute the range of output persistence $\rho$ that the model can explain when $\alpha$ takes different values between 5 and 15 and prices are fixed for 2 , 3 or 4 quarters (see Table 2). It appears that for all countries except the US, the observed persistence can be explained by the model with only two or three quarters of nominal stickiness. In the US, where output fluctuations are less persistent than in the other countries of our sample, even less (real or nominal) rigidity is required.

Second, one can compare the impulse response functions produced by the model with the empirical dynamic profile of output. Figure 3 illustrates the results of this comparison for the US. The solid line shows the univariate impulse response function when output is estimated as an $A R(2)$ process around a trend. The dotted line shows the model-generated impulse response to a monetary shock when prices are fixed for two quarters on average and $\alpha=3, \rho_{m}=0.5$. (The latter value is consistent with the time-series properties of M1 growth in the US; see, e.g., King, 1997). The two impulse response functions are very close. Note, in particular, that the model can reproduce the hump-shaped response in the trend-reverting component of output, already documented by Cochrane (1994) or Cogley and Nason (1995). Thus, we would argue that Figure 3 provides an additional piece of evidence that our model does not need more than a few quarters of nominal rigidity for monetary shocks to generate output fluctuations that are as persistent as in the data. ${ }^{16}$

\footnotetext{
${ }^{16}$ This statement is not the same as -and weaker than- saying that the model can reproduce the empirical impulse response of output to monetary shocks. In order to evaluate the performance of the model along that dimension, the model-generated impulse response function should be compared to the response of output to monetary shocks as estimated in a structural VAR. This is not the case in Figure 3, where the comparison is made with an univariate impulse response.
} 


\section{Concluding comments}

We introduced this paper by raising the question of whether money can have large and persistent effects on economic activity in a dynamic general equilibrium model. Our analysis suggests a positive answer under one condition: small nominal friction may give money large and persistent effects on real activity once they are combined with real frictions. There is nothing in the microfoundations of dynamic general equilibrium models, therefore, that make them inconsistent with the hypothesis that money is a significant source of business fluctuations. While this finding leaves the debate on the role of money in business fluctuations quite open, it shows, first, that this debate can be cast in the dynamic general equilibrium framework developed by the students of the real business cycle, and second, that it might be ultimately a debate about real rigidities, not nominal ones. While different types of real rigidity may be considered, we would argue that there are several reasons to consider those arising in the labor market first. In particular, real wage rigidity can help to make dynamic general equilibrium models more consistent with the evidence on the cyclical behavior of real wages.

There are several ways in which the analysis presented in this paper could be extended. First, it would be interesting to see how the presence of capital accumulation changes the persistence of the response of output to a monetary shock. By lowering the real interest rate, a rise in the quantity of money should stimulate the accumulation of capital, thus adding a persistence mechanism to those analyzed in this paper. The results of Rouwenhorst (1991) suggest, however, that the added channel of persistence would be small relative to the one we have studied in this paper.

Second, it will be necessary to open the real wage function "black box", and model explicitly the features of the labor market that give rise to real wage rigidity. ${ }^{17}$ One reason why this would be useful is that the factors that give rise to real wage rigidity may alter some of the other decision rules. For example, the monitoring difficulties that give rise to efficiency wages may affect the firm's price setting decision. Conversely, the presence of nominal stickiness may affect the process determining the real wage. For example, the

\footnotetext{
${ }^{17} \mathrm{~A}$ first attempt at incorporating an explicit model of real wage rigidity into a dynamic general equilibrium framework is made by Boldrin and Horvath (1995). They look at the impact of implicit contracts in real business cycle models.
} 
wage negotiations between unions and employers may be influenced by the extent to which the latter can adjust their prices. Another reason to model explicitly the factors behind real wage rigidity is that they may generate persistence mechanisms of their own. In particular, the fact that the unions care about past membership, as assumed in the literature on unemployment hysteresis, or the existence of firing costs, could introduce new persistence channels into the model. Finally, explicitly modeling the labor market might help us to understand the link between international differences in output persistence and those in labor market institutions. We plan to explore these questions in future research. 


\section{APPENDIX}

\section{Derivation of equation (22).}

Let us characterize the supply decision of a flex-price producer. We denote by ${ }_{t} D_{t+s}$ and ${ }_{t} P_{t+s}$ the dividend and price level at $t+s$ of a producer that last optimized at $t$. The price setting decision at $t$ determines the dividend at $t+s$ only in states of nature in which the producer is fix-price from $t+1$ to $t+s$ inclusive. Hence the flex-price producer problem may be rewritten:

$$
\max E_{t}\left[\sum_{s=0}^{+\infty}(\beta \phi)^{s} \frac{u^{\prime}\left(c_{t+s+1}\right)}{P_{t+s+1}} D_{t+s}\right]
$$

Using equation (2) and ${ }_{t} P_{t+s}=(1+\bar{\pi})^{s}{ }_{t} P_{t}$, the period $t+s$ dividend may be expressed as a function of period $t$ price:

$$
{ }_{t} D_{t+s}=Y_{t+s}\left(\frac{P_{t+s}}{(1+\bar{\pi})^{s}{ }_{t} P_{t}}\right)^{a}\left((1+\bar{\pi})_{t}^{s} P_{t}-P_{t+s} W_{t+s}\right)
$$

Tedious computations then show that the first order condition:

$$
E_{t}\left(\sum_{s=0}^{+\infty}(\beta \phi)^{s} \frac{u^{\prime}\left(c_{t+s+1}\right)}{P_{t+s+1}} \frac{\partial_{t} D_{t+s}}{\partial_{t} P_{t}}\right)=0
$$

implies that $\tilde{P}_{f l e x, t}={ }_{t} P_{t} / P_{t}$ is given by $(22)$. 


\section{Linearizing the model}

Equations (23), (24), (26) and (27) result straightforwardly from the linearization of (21), the binding cash-in-advance constraint, (13) and (20). In order to derive (25), we first linearize (17) and (22), to obtain:

$$
\begin{aligned}
\phi \widehat{\pi}_{t} & =(1-\phi) \hat{\tilde{p}}_{f l e x, t} \\
\widehat{\tilde{p}}_{\text {flex }, t} & =(1-\beta \phi) E_{t} \sum_{s=0}^{+\infty}(\beta \phi)^{s}\left(\widehat{w}_{t+s}+\widehat{\pi}_{t, t+s}\right)
\end{aligned}
$$

where $\hat{\pi}_{t, t+s}=\sum_{k=1}^{s} \hat{\pi}_{t+k}$ corresponds to the cumulative inflation rate between $t$ and $t+s$. Substituting $\hat{\tilde{p}}_{f l e x, t}$ out of these equations then gives:

$$
E_{t} \sum_{s=0}^{+\infty}(\beta \phi)^{s}\left(\widehat{w}_{t+s}+\hat{\pi}_{t, t+s}\right)=\frac{\phi}{(1-\phi)(1-\beta \phi)} \widehat{\pi}_{t}
$$

From this equation, plus the fact that $\hat{\pi}_{t, t}=0$ and $\widehat{\pi}_{t, t+s+1}=\widehat{\pi}_{t+1}+$ $\widehat{\pi}_{t+1, t+s+1}$, it follows that:

$$
\begin{aligned}
\frac{\phi}{(1-\phi)(1-\beta \phi)}\left(\widehat{\pi}_{t}-\beta \phi E_{t} \widehat{\pi}_{t+1}\right) & =\widehat{w}_{t}+\beta \phi E_{t} \sum_{s=0}^{+\infty}(\beta \phi)^{s} \widehat{\pi}_{t+1} \\
& =\widehat{w}_{t}+\frac{\beta \phi}{1-\beta \phi} E_{t} \widehat{\pi}_{t+1}
\end{aligned}
$$

hence:

$$
\widehat{w}_{t}=\frac{\phi}{(1-\phi)(1-\beta \phi)}\left(\widehat{\pi}_{t}-\beta E_{t} \widehat{\pi}_{t+1}\right)
$$

which, together with (26), gives (25). 


\section{References}

Ball, L., and D. Romer, 1990, Real rigidities and the non-neutrality of money, Review of Economic Studies 57, 183-203.

Benassy, J.-P., 1995, Money and wage contracts in an optimizing model of the business cycle, Journal of Monetary Economics 35, 303-315.

Bils, M.J., 1985, Real wages over the business cycle: evidence from panel data, Journal of Political Economy 93, 666-89.

Blanchard, O.J., 1983, Price asynchronization and price level inertia, in R. Dornbusch and M.H. Simonsen, eds., Inflation, Debt, and Indexation, MIT Press (Cambridge, MA).

Blanchard, O.J., 1990, Why does money affect output? A survey, in B. Friedman and F. Hahn, eds., Handbook of Monetary Economics, North Holland (Amsterdam).

Blanchard, O.J., and S. Fischer, 1989, Lectures on Macroeconomics, The MIT Press (Cambridge MA).

Boldrin, M., and M. Horvath, 1995, Labor contracts and business cycles, Journal of Political Economy 103, 972-1004.

Calvo, G., 1983, Staggered prices in a utility-maximizing framework, Journal of Monetary Economics 12, 383-398.

Carlton, D.W., 1986, The rigidity of prices, American Economic Review 76 , 637-658.

Cecchetti, S., 1986, The frequency of price adjustment: a study of the newsstand prices of magazines, 1953 to 1979, Journal of Econometrics $31,255-274$.

Chari, V.V., Kehoe, P.J. and E.R. McGrattan, 1996, Sticky price models of the business cycle: can the contract multiplier solve the persistence problem?, Federal Reserve Bank of Minneapolis, Research Department Staff Report 217. 
Cho, J.-O., 1993, Money and the business cycle with one-period nominal contracts, Canadian Journal of Economics 26, 638-659.

Cho, J.-O., and T. Cooley, 1995, The business cycle with nominal contracts, Economic Theory 6, 13-33.

Christiano, L.J. and M. Eichenbaum, 1992, Current Real-Business-Cycle theories and labor-market fluctuations. American Economic Review $82,430-450$.

Cochrane, J.H., 1988, How big is the random walk in GNP?, Journal of Political Economy 96, 893-920.

Cochrane, J.H., 1994, Permanent and transitory components of GNP and stock prices, Quarterly Journal of Economics 109, 241-265.

Cogley, T., and J.N. Nason, 1995, Output dynamics in Real-Business-Cycle Models, American Economic Review 85, 492-511.

Cooley, T., and G. Hansen, 1989, The inflation tax in a real business cycle model, American Economic Review 79, 733-748.

Cooley, T., and G. Hansen, 1995, Money and the business cycle, in Cooley, ed., Frontiers of Business Cycle Research. Princeton University Press (Princeton).

Danthine, J.-P., and J. B. Donaldson, 1990, Efficiency wages and the business cycle puzzle, European Economic Review 34, 1275-1301.

Geary, P., and J. Kennan, 1982, The employment-wage relationship: an international study, Journal of Political Economy 90, 854-871.

Hairault, J.-O., and F. Portier, 1993, Money, new Keynesian macroeconomics and the business cycle, European Economic Review 37, 15331568 .

Hall, R., 1997, Impulses, amplification and persistence, draft chapter for Handbook of Macroeconomics, J. Taylor and M. Woodford, eds., presented at the conference "Recent Developments in Macroeconomics", Federal Reserve Bank of San Francisco, March 7-8 1997. 
Horvath, M., 1997, Cyclicality and sectoral linkages: Aggregate fluctuations from independent sectoral shocks, mimeo, Department of Economics, Stanford University.

Ireland, P., 1996, The role of countercyclical monetary policy, Journal of Political Economy 104, 704-723.

Jeanne, O., 1994, Nominal rigidities and the liquidity effect, mimeo Ceras.

Kashyap, A.K., 1995, Sticky prices: new evidence from retail catalogs, Quarterly Journal of Economics 110, 245-274.

Keane, M., Moffitt, R., and D. Runkle, 1988, Real wages over the business cycle: estimating the impact of heterogeneity with micro data, Journal of Political Economy 96, 1231-1266.

Kiley, M.T., 1997, Staggered price setting, partial adjustment and real rigidities, mimeo, Federal Reserve Board, Washington.

Kimball, M.S., 1995, The quantitative analytics of the basic neomonetarist model, Journal of Money, Credit and Banking 27, 1241-1277.

King, R., 1997, Money and business cycles, Journal of Monetary Economics, forthcoming.

King, R., and M. Goodfriend, 1997, The New Neoclassical Synthesis and the role of monetary policy, paper prepared for the 1997 NBER Macroeconomics Annual.

King, R., and M.W. Watson, 1996, Money, prices, interest rates and the business cycle, Review of Economics and Statistics 78, 35-53.

King, R.G., Plosser, C.I., and S.T. Rebelo, 1988, Production, growth and business cycles I. The basic neoclassical model, Journal of Monetary Economics 21, 195-232.

Kollmann, R., 1996, The exchange rate in a dynamic-optimizing current account model with nominal rigidities: a quantitative investigation, mimeo. 
Kydland, F.E., 1991, The role of money in a business cycle model, Discussion Paper 23, Institute for Empirical Macroeconomics, Federal Reserve Bank of Minneapolis.

Lach, S., and D. Tsiddon, 1992, The behavior of prices and inflation: an empirical analysis of disaggregated price data, Journal of Political Economy 100, 349-389.

McCallum, B., and E. Nelson, 1997, An optimizing IS-LM specification for monetary policy and business cycle analysis, NBER Working Paper No.5875.

McDonald, I., and R. Solow, 1981, Wage bargaining and employment, American Economic Review 71, 896-908.

Nelson, E., 1997, A framework for analyzing alternative models of nominal rigidities, mimeo, Carnegie Mellon University.

Obstfeld, M., and K. Rogoff, 1995, Exchange rate dynamics redux, Journal of Political Economy 103, 624-660.

Ohanian, L.E., Stockman, A.C., and L. Kilian, 1995, The effects of real and monetary shocks with some sticky prices, Journal of Money, Credit and Banking 27, 1209-1234.

Pencavel, J., 1986, Labor supply of men: a survey, in Handbook of Labor Economics (North-Holland, Amsterdam).

Roberts, 1995, New Keynesian economics and the Phillips curve, Journal of Money, Credit and Banking 27, 975-984.

Romer, D., 1996, Advanced Macroeconomics, McGraw-Hill, New-York.

Rotemberg, J., 1982, Sticky prices in the United States, Journal of Political Economy 90, 1187-1211.

Rotemberg, J., 1996, Prices, output and hours: an empirical analysis based on a sticky price model, Journal of Monetary Economics 37, 505-533.

Rouwenhorst, K.G., 1991, Time to build and aggregate fluctuations: A reconsideration, Journal of Monetary Economics 27, 241-254. 
Solon, G., Barsky R. and J.A. Parker, 1994, Measuring the cyclicality of real wages: how important is composition bias? Quarterly Journal of Economics 109, 1-25.

Taylor, J.B., 1980, Aggregate dynamics and staggered contracts, Journal of Political Economy 88, 1-23.

Yun, T., 1996, Nominal price rigidity, money supply endogeneity, and business cycles, Journal of Monetary Economics 37, 345-370. 
Table 1

\begin{tabular}{l|c|c|} 
& $\rho$ & $1 / \alpha$ \\
\hline U.S.A. & 0.769 & 0.101 \\
& & $(0.112)$ \\
\hline Japan & 0.890 & $\begin{array}{c}0.129 \\
(0.118)\end{array}$ \\
\hline Germany & 0.931 & $\begin{array}{c}0.098 \\
(0.101)\end{array}$ \\
\hline France & 0.927 & $\begin{array}{c}-0.145 \\
(0.189)\end{array}$ \\
\hline Italy & 0.852 & $\begin{array}{c}0.192 \\
(0.204)\end{array}$ \\
\hline U.K. & 0.902 & $\begin{array}{c}0.459 \\
(0.144)\end{array}$ \\
\hline
\end{tabular}

The standard errors are indicated in parenthesis.

Table 2

\begin{tabular}{l|l|l|l|}
$\rho$ & $\tau=2$ & $\tau=3$ & $\tau=4$ \\
\hline$\alpha=5$ & 0.836 & 0.881 & 0.907 \\
\hline$\alpha=10$ & 0.882 & 0.916 & 0.935 \\
\hline$\alpha=15$ & 0.903 & 0.931 & 0.947 \\
\hline
\end{tabular}


Figure 1

The iso-persistence curves in $(\phi, \alpha)$ space.

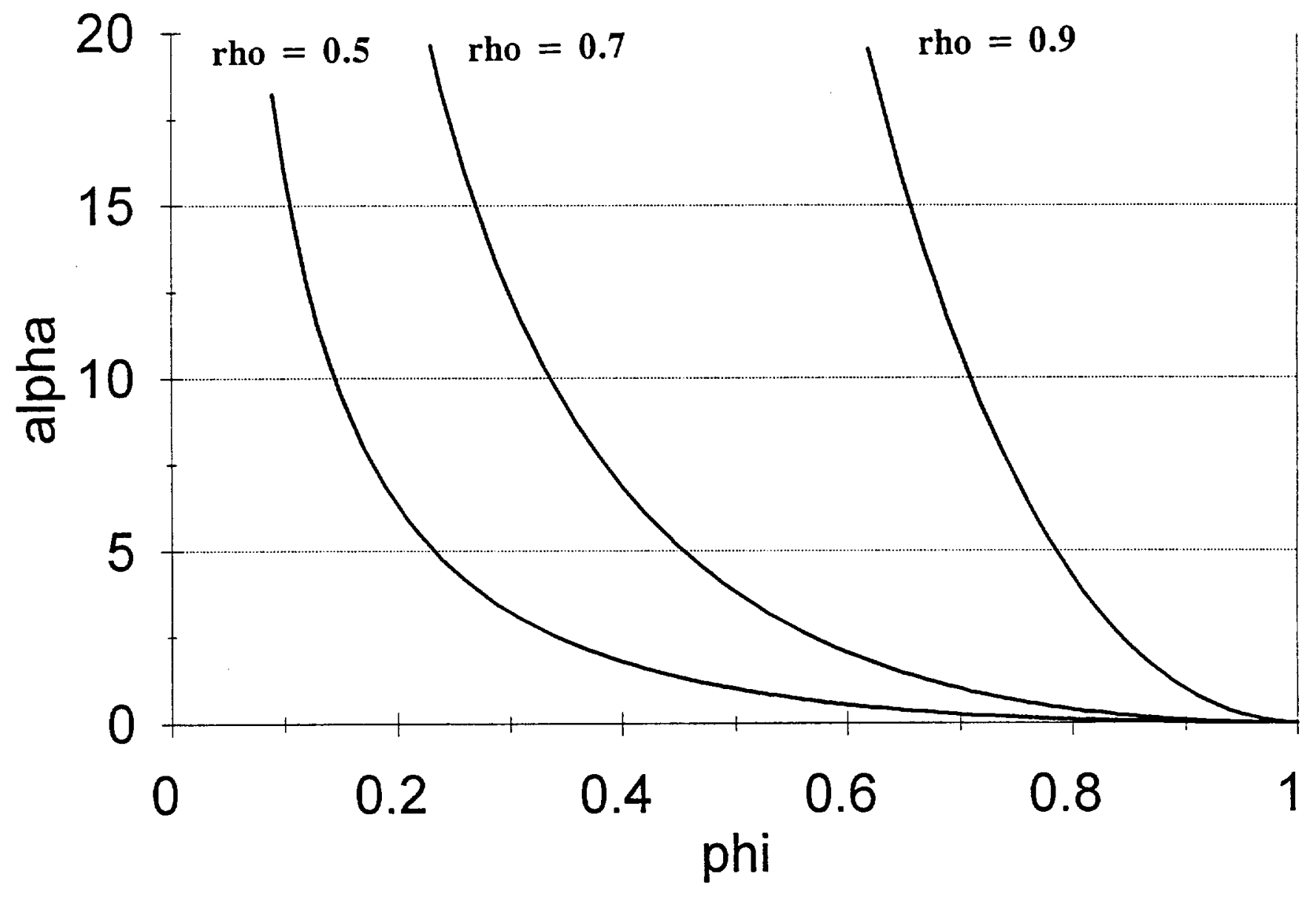


Figure 2

Output persistence $\rho$ for Taylor's and Calvo's contracts.

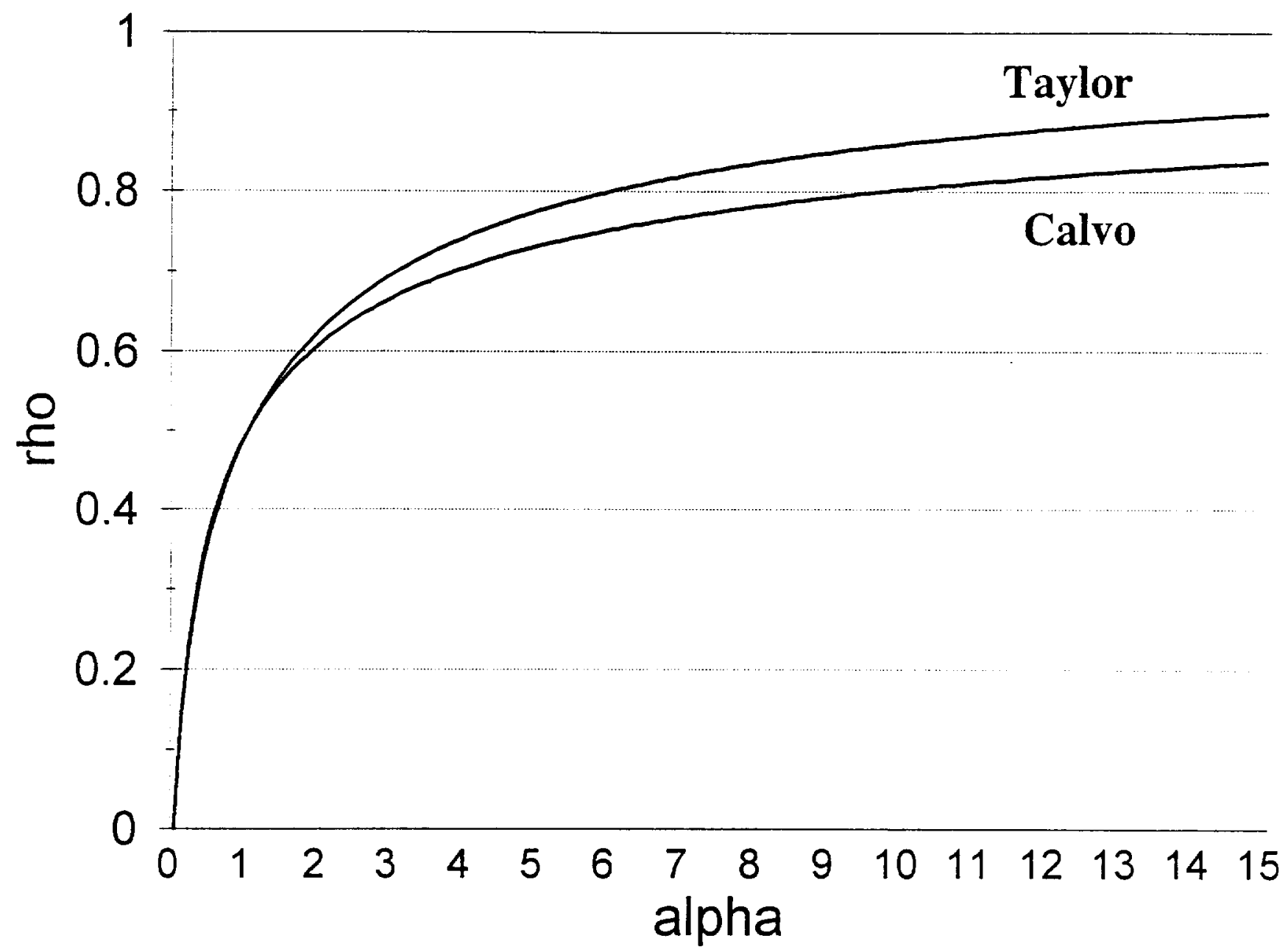




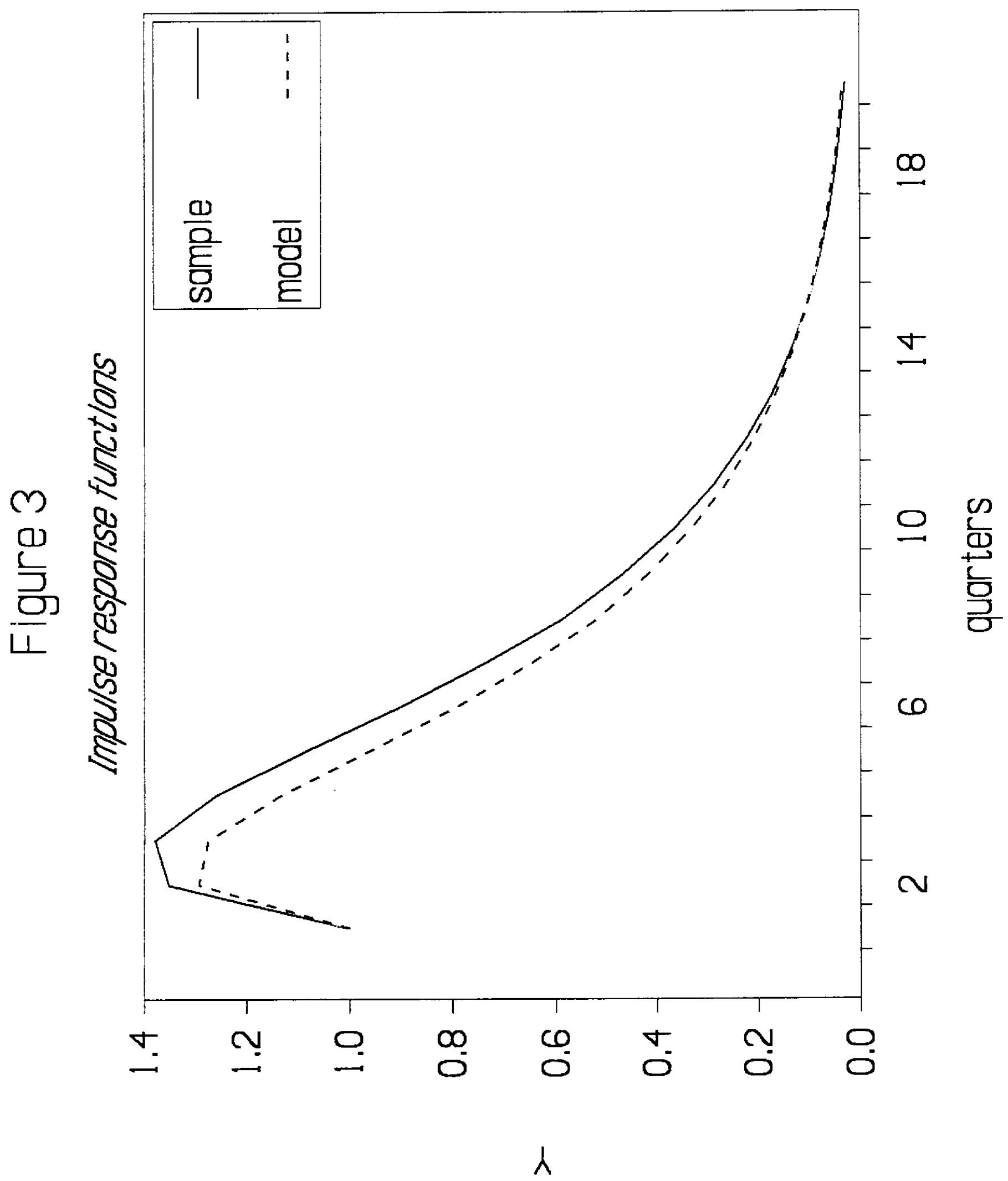

